University of Nebraska - Lincoln

DigitalCommons@University of Nebraska - Lincoln

Faculty Publications: Department of

Entomology

Entomology, Department of

2009

Bioavailability of Chlorantraniliprole and Indoxacarb to Eastern

Subterranean Termites (Isoptera: Rhinotermitidae) in Various

Soils

Neil A. Spomer

University of Nebraska-Lincoln

Shripat T. Kamble

Universitiy of Nebraska--Lincoln, skamble1@unl.edu

Blair D. Siegfried

University of Nebraska-Lincoln, bsiegfried1@ufl.edu

Follow this and additional works at: https://digitalcommons.unl.edu/entomologyfacpub

Part of the Entomology Commons

Spomer, Neil A.; Kamble, Shripat T.; and Siegfried, Blair D., "Bioavailability of Chlorantraniliprole and Indoxacarb to Eastern Subterranean Termites (Isoptera: Rhinotermitidae) in Various Soils" (2009). Faculty Publications: Department of Entomology. 317.

https://digitalcommons.unl.edu/entomologyfacpub/317

This Article is brought to you for free and open access by the Entomology, Department of at DigitalCommons@University of Nebraska - Lincoln. It has been accepted for inclusion in Faculty Publications: Department of Entomology by an authorized administrator of DigitalCommons@University of Nebraska - Lincoln. 


\title{
Bioavailability of Chlorantraniliprole and Indoxacarb to Eastern Subterranean Termites (Isoptera: Rhinotermitidae) in Various Soils
}

\author{
NEIL A. SPOMER, ${ }^{1}$ SHRIPAT T. KAMBLE, ${ }^{1,2}$ AND BLAIR D. SIEGFRIED ${ }^{1}$
}

\begin{abstract}
J. Econ. Entomol. 102(5): 1922-1927 (2009)
ABSTRACT A laboratory study was conducted to determine the toxicity of indoxacarb and chlorantraniliprole to Eastern subterranean termites, Reticulitermes flavipes (Kollar) (Isoptera: Rhinotermitidae) resulting from topical applications and exposure to treated soil. Soils with varying organic matter (0.57-3.64\%) and chemical characteristics were used in termiticide bioassays. Lethal dose resulting from topical application indicated that chlorantraniliprole was two- to 11-fold more toxic than indoxacarb. Lethal concentration assays yielded opposite results where concentrations of indoxacarb in soil that caused either 50 or $90 \%$ mortality of R. flavipes workers at 48 and $144 \mathrm{~h}$ were two- to six-fold lower than chlorantraniliprole. The bioavailability of indoxacarb and chlorantraniliprole was negatively correlated with soil organic matter. Our results suggest that indoxacarb is more bioavailable to termites in soil than chlorantraniliprole based on calculated bioavailability ratios. However, how these laboratory results correlate to actual field application data and termite efficacy is unknown, and more research is needed. These compounds seem to have excellent activity on termites and have potential to provide new modes of action and new chemistry as liquid termiticides.
\end{abstract}

KEY WORDS bioavailability, termiticide, termites, toxicity, Reticulitermes flavipes

The use of soil termiticides is a common remedial and preventative control measure to protect structures from termite damage. These treatments typically involve creating a termiticide barrier in soil around and under buildings. Currently registered termiticides such as Termidor (fipronil), Premise (imidacloprid), and Phantom (chlorfenapyr) are nonrepellent and thus allow termites to forage through treated soils and acquire exposure to the toxicant.

The environmental fate and bioavailability of termiticides in a particular soil are important considerations when deciding if a high or low label application rates is appropriate. Soil properties including $\mathrm{pH}$, clay, sand, and organic matter (OM) are key factors affecting the fate and biological availability of insecticides. Harris and Bowman (1981) reported a significant negative correlation between toxicity of treated soil to insects and insecticide solubility in water. Harris (1966) reported that organic matter content of soil generally has an inverse relationship with insecticide toxicity. Several studies report the performance of insecticides in soils with varying soil properties, including OM content (Getzin and Chapman 1960; Harris 1966, 1970; Harris and Mazurek 1966; Whitney 1967; Harris and Hitchon 1970; Campbell et al. 1971; Felsot and Dahm 1979; Felsot and Lew 1989; Forschler and Townsend 1996; Gold et al. 1996). Gold et al. (1996) evaluated bioavailability of organophosphate and py-

\footnotetext{
${ }^{1}$ Department of Entomology, University of Nebraska, Lincoln, NE 68583-0816.

${ }^{2}$ Corresponding author, e-mail: skamble1@unl.edu.
}

rethroid termiticides in five different soil types. In terms of efficacy and activity, the termiticides performed the best in slightly acidic soils $(\mathrm{pH} 6.4)$ with low organic content $(0.8 \% \mathrm{OM})$.

Chlorantraniliprole and indoxacarb are two of the newest termiticides currently being developed. Chlorantraniliprole is a new insecticide from the anthranilic diamide class of insecticides with a novel mode of action that targets and activates the ryanodine receptor in insects. Chlorantraniliprole binds to the ryanodine receptor causing the release of internal stored calcium. The release of stored calcium causes insects to loose control of muscle regulation. The resulting muscle contractions can lead to rapid feeding cessation, lethargy, partial paralysis, cardiac muscle failure, and regurgitation (Cordova et al. 2006). Chlorantraniliprole has a water solubility of $1.023 \mathrm{mg} \operatorname{liter}^{-1}$ (deionized [DI] water, $20^{\circ} \mathrm{C}$ ), octanol/water partitioning coefficient $\left(\mathrm{K}_{\mathrm{ow}}\right)$ of 589 (DI water, $20^{\circ} \mathrm{C}$ ), average organic carbon partitioning coefficient $\left(\mathrm{K}_{\mathrm{oc}}\right)$ of 328, and Henry's law constant of $3.1 \times 10^{-15} \mathrm{~atm} \mathrm{~m}^{3}$ $\mathrm{mol}^{-1}$ (USEPA 2008).

Indoxacarb is an oxadiazine proinsecticide that is metabolically activated after entering the insect. The activated decarbomethoxylated indoxacarb metabolite acts by blocking the sodium channel of the insect nervous system (Wing et al. 2000). Although the sodium channel is a common target of other chemical classes (i.e., DDT and pyrethroids), it seems indoxacarb acts on a novel binding site of the receptor because there is no cross-resistance between classes (Nauen and Bretschneider 2002). Indoxacarb has a 
Table 1. Soil characteristics

\begin{tabular}{|c|c|c|c|c|c|c|}
\hline \multirow{2}{*}{ Soil $^{a}$} & \multirow{2}{*}{$\mathrm{pH} \pm \mathrm{SEM}$} & \multicolumn{3}{|c|}{ Particle size analysis (\%) } & \multirow{2}{*}{$\mathrm{CEC}\left(\mathrm{cmol} \mathrm{kg}^{-1}\right)$} & \multirow{2}{*}{$\% \mathrm{OM} \pm \mathrm{SEM}$} \\
\hline & & Sand & Silt & $\overline{\text { Clay }}$ & & \\
\hline SL & $6.94 \pm 0.04$ & 75.40 & 7.45 & 17.15 & 6.93 & $0.57 \pm 0.04$ \\
\hline SCL-1 & $7.08 \pm 0.04$ & 15.85 & 46.95 & 37.20 & 25.54 & $2.58 \pm 0.03$ \\
\hline SCL-2 & $6.98 \pm 0.03$ & 15.15 & 48.95 & 35.90 & 35.48 & $3.64 \pm 0.03$ \\
\hline
\end{tabular}

${ }^{a}$ SL, sandy loam; SCL, sandy clay loam.

solubility of $0.2 \mathrm{mg}$ liter ${ }^{-1}\left(25^{\circ} \mathrm{C}\right), \mathrm{K}_{\mathrm{ow}}$ of $45,000, \mathrm{~K}_{\mathrm{oc}}$ range of 2,200-9,400, and Henry's law constant of $<6.1 \times 10^{-10} \mathrm{~atm} \mathrm{~m}^{3} \mathrm{~mol}^{-1}$ (USEPA 2000).

The objectives of this study were to 1 ) determine $\mathrm{LD}_{50}$ and $\mathrm{LD}_{90}$ values of indoxacarb and chlorantraniliprole to Eastern subterranean termite, Reticulitermes flavipes (Kollar) (Isoptera: Rhinotermitidae); 2) establish $\mathrm{LC}_{50}$ and $\mathrm{LC}_{90}$ values of indoxacarb and chlorantraniliprole for $R$. flavipes in three different soil types; and 3) ascertain whether bioavailability of chlorantraniliprole and indoxacarb is influenced by soil organic matter.

\section{Materials and Methods}

Termiticides. Technical grade indoxacarb, (S)methyl 7-chloro-2, 5-dihydro-2-[ [ (methoxy-carbonyl) [4(trifluoromethoxy) phenyl] amino]-carbonyl]indeno$[1,2-e][1,3,4]$ oxadiazine-4a- $\left({ }^{3} \mathrm{H}\right)$-carboxylate, was obtained from Chem Service (West Chester, PA) [98\% pure $(S)$-isomer, lot 352-67A). Technical grade chlorantraniliprole (DPX E2Y45-30), 3-bromo-N-[4chloro-2-methyl-6-(methylcarbamoyl) phenyl]-1-(3chloro-2-pyridine-2-yl)-1H-pyrazole-5-carboxamide, was obtained from DuPont Corp., Wilmington, DE (>93\% purity).

Termite Collection and Rearing. Subterranean termites were collected from fallen logs in Wilderness Park Recreation area in Lancaster Co., NE, on 23 August 2008. Termites were extracted from the logs and maintained in Plexiglas containers ( 35 by 25 by 10 $\mathrm{cm}$ ) provisioned with moistened sand and corrugated cardboard and held in complete darkness at $23^{\circ} \mathrm{C}$. Termites were allowed to acclimate for $1 \mathrm{wk}$ before using in bioassays. The termites were confirmed to be $R$. flavipes by using soldier morphology (Weesner 1965, Nutting 1990). The average weight of each termite worker was $3.97 \pm 0.11 \mathrm{mg}(n=240)$.

Soil Collection and Preparation. Soils were collected from Cumming and Lancaster counties in Nebraska and were analyzed by the Soil and Plant Analytical Laboratory at the University of Nebraska, Lincoln, NE. Soils were characterized for \%OM, pH, cation exchange capacity, and particle size (Table 1). The three soils were identified and designated sandy loam (SL), silty clay loam (SCL) -1, and SCL-2 (USDA 1993) were autoclaved, air-dried, and sieved (2 mm) before use in experiments.

Lethal Dose Based on Topical Application Bioassay. Dilutions of chlorantraniliprole (11 concentrations ranging from 0.196 to $200.8 \mu \mathrm{g} \mathrm{g}^{-1}$ ) and indoxacarb (11 concentrations ranging from 0.196 to $200.9 \mu \mathrm{g} \mathrm{g}^{-1}$ ) in acetone (99.9\%; Sigma, St. Louis, MO) were prepared. Termites were chilled in a cooler $\left(\approx 4^{\circ} \mathrm{C}\right)$ for $5 \mathrm{~min}$ before topical application of insecticide. Diluted chlorantraniliprole and indoxacarb $(0.2 \mu \mathrm{l})$ was topically applied to the dorsal portion of the third to fourth abdominal segments of each $R$. flavipes worker (fourth to fifth instar) by using a microapplicator (Hamilton Co., Reno, NV) fitted with a 10- $\mu$ l syringe. Termites in controls were treated with $0.2 \mu$ l of acetone. Groups of 15 termite workers were placed in a Plexiglas container (35 $\mathrm{mm}$ in diameter by $10 \mathrm{~mm}$ in depth) provisioned with untreated sand ( $20 \%$ moisture content) and white pine as a food source. Termites were monitored for mortality at 48 and $144 \mathrm{~h}$.

Lethal Concentration Based on Soil Contact Bioassay. Air-dried soils were treated with either chlorantraniliprole (10 concentrations ranging from 0.088 to $45.0 \mu \mathrm{g} \mathrm{g}^{-1}$ ) or indoxacarb (10 concentrations ranging from 0.098 to $50.0 \mu \mathrm{g} \mathrm{g}^{-1}$ ) in acetone. After insecticide application, the soils were agitated to ensure uniform treatment. Control samples from each soil type were treated with acetone only. Soils were then air-dried under a fume hood for $15 \mathrm{~h}$ to allow for acetone evaporation. Three grams of each soil and active ingredient (AI) concentration was weighed into Plexiglas containers $(35 \mathrm{~mm}$ in diameter by $10 \mathrm{~mm}$ in depth) moistened with $0.75 \mathrm{ml}$ of distilled water and provisioned with a piece of white pine ( 2 by 1 by 0.5 $\mathrm{cm}$ ). Control containers (units) containing soil treated with acetone were prepared in a similar manor. All containers (units) were acclimated for $24 \mathrm{~h}$ in an environmental growth chamber at $23^{\circ} \mathrm{C}$ in complete darkness. In total, four replicates were constructed for each soil by termiticide by concentration combination for a total of 252 individual containers (units). Fifteen R. flavipes workers (fourth to fifth instar) were added to each unit, and mortality was assessed at 48 and $144 \mathrm{~h}$. Termites were recorded as dead if they could not right themselves within $10 \mathrm{~s}$ of being flipped onto their back.

Bioavailability Ratios. Bioavailability ratios were calculated by dividing $\mathrm{LD}_{50}$ values by $\mathrm{LC}_{50}$ values of each termiticide for a particular soil type and time interval (see Table 4). LD 50 (nanograms of insecticide per termite) values were converted to nanograms of insecticide per gram of termite. $\mathrm{LC}_{50}$ values also were converted from micrograms of insecticide per gram of soil to nanograms of insecticide per gram of soil. The purpose of the bioavailability ratio is to compare LC values taking into account the $\mathrm{LD}$ values for each termiticide for a specific time period. Evaluating termiticides based on this ratio may be extremely valu- 
Table 2. Lethal doses of indoxacarb and chlorantraniliprole to $R$. flavipes workers resulting from topical application

\begin{tabular}{|c|c|c|c|c|c|c|}
\hline Chemical & Time $(\mathrm{h})$ & $\mathrm{n}$ & Slope $( \pm \mathrm{SE})$ & $\begin{array}{c}\left.\mathrm{LD}_{50} \text { (ng per termite }\right) \\
(95 \% \mathrm{CI})^{a}\end{array}$ & $\begin{array}{c}\mathrm{LD}_{90}(\text { ng per termite }) \\
(95 \% \mathrm{CI})^{a}\end{array}$ & $\chi^{2}$ \\
\hline \multirow[t]{2}{*}{ Indoxacarb } & 48 & 480 & $1.52(0.14)$ & $8.22(5.93-12.17)$ & $57.18(32.49-138.17)$ & 7.38 \\
\hline & 144 & 420 & $1.71(0.13)$ & $2.50(1.39-4.84)$ & $13.98(6.79-48.00)$ & 15.24 \\
\hline \multirow[t]{2}{*}{ Chlorantraniliprole } & 48 & 480 & $1.07(0.09)$ & $2.13(1.61-2.84)$ & $34.02(21.08-64.47)$ & 5.83 \\
\hline & 144 & 420 & $2.37(0.21)$ & $0.37(0.26-0.52)$ & $1.28(0.88-2.15)$ & 5.82 \\
\hline
\end{tabular}

${ }^{a}$ LD values with overlapping CIs are not significantly different.

able to determine actual bioavailability in different soil types.

Statistical Analysis. Lethal doses and concentrations and $95 \%$ fiducial limits were calculated using PoloPlus (LeOra Software 2003; LeOra Software, Petaluma, CA), a probit and logit analysis software program. Regression analysis of bioavailability factor and organic matter correlation was conducted using SigmaPlot 9.0 (Systat Software, Inc. 2004; Systat Software, Inc., Point Richmond, CA).

\section{Results and Discussion}

Lethal Dose Topical Application Bioassay. The $\mathrm{LD}_{50}$ and $\mathrm{LD}_{90}$ data of topically applied indoxacarb and chlorantraniliprole to R. Alavipes workers are presented in Table 2 . The $\mathrm{LD}$ values decreased with time (48 versus $144 \mathrm{~h}$ ) for both indoxacarb and chlorantraniliprole. LD values were generally higher for indoxacarb compared with chlorantraniliprole at both 48 and $144 \mathrm{~h}$. Chlorantraniliprole $\mathrm{LD}_{50}$ values were 3.9 and 6.8-fold lower than indoxacarb at 48 and $144 \mathrm{~h}$, respectively, whereas $\mathrm{LD}_{90}$ values were 1.7- and 10.9fold lower at 48 and $144 \mathrm{~h}$. $\mathrm{LD}_{50}$ values were all significantly different with the exception of $\mathrm{LD}_{50}$ indoxacarb at $144 \mathrm{~h}$ and chlorantraniliprole at $48 \mathrm{~h}$ based on nonoverlapping fiducial limits. These results reflect the generally higher intrinsic toxicity of chlorantraniliprole relative to indoxacarb.

Lethal Concentration Soil Contact Bioassay. The $\mathrm{LC}_{50}$ and $\mathrm{LC}_{90}$ data are presented in Table 3. Although all not statistically different, numerical LC values differed based on soil type (SL < SCL-1 < SCL-2). As expected, $\mathrm{LC}_{50} \mathrm{~s}$ decreased with time for both indoxacarb and chlorantraniliprole, with 48 -h values being significantly higher based on nonoverlapping fiducial limits. This trend was also observed for $\mathrm{LC}_{90}$ values; however, the wide 95\% limits indicate that not all differences were significant. Interestingly, LC values were higher for chlorantraniliprole than indoxacarb, which is opposite of the topical toxicity data. Indoxacarb LC $_{50}$ values were 1.7-2.6- (48 h) and 2.7-5.9 (144 h)-fold lower than chlorantraniliprole values in the various soils. Indoxacarb $\mathrm{LC}_{90}$ values were $1.8-4.3-$ $(48 \mathrm{~h})$ and 1.7-3.7 (144 h)-fold lower than $\mathrm{LC}_{90}$ chlorantraniliprole values.

Bioavailability Ratios. LD values determined by topical applications should be consistent for a particular colony of termites at a particular point in time. In contrast, LC values of insecticide treated soils will probably fluctuate based on soil conditions and properties such as type, and percentage of organic matter, among others. The bioavailability ratio as calculated in the current study is based on the proportion of insecticide required to contact the termite cuticle as determined by topical application to the soil concentration that causes $50 \%$ population mortality based on termite weight at a particular time interval. Lethal doses determined by topical application indicates the amount of AI required to contact the termite cuticle and kill a certain percentage of the test population at a particular time interval. These data are specific for an AI and generally reflect the toxicokinetics (e.g., penetration, biotransformation and target site interaction) of the AI. Lethal concentrations as determined by exposure to treated soil reflect the propensity of an AI to be taken up from soil by an organism in spite of environmental factors such as soil properties and moisture content. LC values are also specific for a particular time interval and reflect the AI concentra-

Table 3. Lethal concentrations of indoxacarb or chlorantraniliprole to $R$. flavipes workers after contact exposure to treated soils

\begin{tabular}{|c|c|c|c|c|c|c|c|}
\hline Chemical & Soil & Time $(\mathrm{h})$ & $n$ & Slope $( \pm$ SE $)$ & $\begin{array}{c}\mathrm{LC}_{50} \\
(\mu 5 \% \text { per g soil }) \\
(95 \%)^{a}\end{array}$ & $\begin{array}{c}\mathrm{LC}_{90} \\
(\mu \mathrm{g} \text { per g soil }) \\
(95 \% \mathrm{CI})^{a}\end{array}$ & $\chi^{2}$ \\
\hline \multirow[t]{2}{*}{ Indoxacarb } & Sl & 48 & 360 & $1.34 \pm 0.14$ & $5.88(3.64-10.94)$ & $50.91(22.56-254.60)$ & 6.34 \\
\hline & & 144 & 360 & $1.33 \pm 0.13$ & $0.34(0.15-0.64)$ & $3.12(1.57-9.91)$ & 7.75 \\
\hline \multirow[t]{2}{*}{ Indoxacarb } & Scl-1 & 48 & 360 & $1.35 \pm 0.13$ & $8.14(4.56-14.05)$ & $71.96(35.53-257.36)$ & 7.01 \\
\hline & & 144 & 360 & $1.27 \pm 0.12$ & $0.52(0.22-0.97)$ & $5.29(2.60-17.18)$ & 12.09 \\
\hline \multirow[t]{2}{*}{ Indoxacarb } & Scl-2 & 48 & 420 & $1.92 \pm 0.23$ & $17.67(14.07-23.89)$ & $82.32(52.37-165.92)$ & 2.04 \\
\hline & & 144 & 540 & $1.57 \pm 0.11$ & $1.29(1.06-1.56)$ & $8.40(6.34-11.88)$ & 5.23 \\
\hline \multirow{2}{*}{ Chlorantraniliprole } & SL & 48 & 420 & $1.27 \pm 0.14$ & $11.03(8.25-15.80)$ & $111.77(61.85-270.05)$ & 2.27 \\
\hline & & 144 & 360 & $1.89 \pm 0.16$ & $1.12(0.71-1.81)$ & $5.34(3.05-13.10)$ & 7.16 \\
\hline \multirow[t]{2}{*}{ Chlorantraniliprole } & Scl-1 & 48 & 420 & $1.62 \pm 0.18$ & $20.85(15.59-29.76)$ & $129.51(77.62-276.86)$ & 1.89 \\
\hline & & 144 & 360 & $1.79 \pm 0.13$ & $3.07(1.45-6.46)$ & $15.94(7.41-59.58)$ & 13.54 \\
\hline \multirow[t]{2}{*}{ Chlorantraniliprole } & SCL-2 & 48 & 480 & $1.20 \pm 0.13$ & $30.22(18.99-62.63)$ & $354.46(137.64-647.37)$ & 2.04 \\
\hline & & 144 & 360 & $1.36 \pm 0.12$ & $3.51(1.50-7.09)$ & $31.00(13.79-155.17)$ & 5.23 \\
\hline
\end{tabular}

${ }^{a}$ LC values with overlapping CIs are not significantly different. 
Table 4. Bioavailability ratios derived from $\mathbf{L D}_{50}$ and $\mathrm{LC}_{50}$ values of indoxacarb and chlorantraniliprole from three soils

\begin{tabular}{|c|c|c|c|c|c|}
\hline Chemical & Soil & Time $(\mathrm{h})$ & $\mathrm{LD}_{50}(\mathrm{ng} \text { per g termite })^{a}$ & $\mathrm{LC}_{50}(\mathrm{ng} \text { per g soil })^{a}$ & $\begin{array}{c}\text { Bioavailability ratio, } \\
\mathrm{LD}_{50} / \mathrm{LC}_{50}\end{array}$ \\
\hline \multirow[t]{2}{*}{ Indoxacarb } & \multirow[t]{2}{*}{ SL } & 48 & $2,070.5$ & 5,880 & 0.352 \\
\hline & & 144 & 629.7 & 340 & 1.852 \\
\hline \multirow[t]{2}{*}{ Indoxacarb } & \multirow[t]{2}{*}{ SCL-1 } & 48 & $2,070.5$ & 8,140 & 0.254 \\
\hline & & 144 & 629.7 & 520 & 1.211 \\
\hline \multirow[t]{2}{*}{ Indoxacarb } & \multirow[t]{2}{*}{ SCL-2 } & 48 & $2,070.5$ & 17,670 & 0.117 \\
\hline & & 144 & 629.7 & 1,290 & 0.488 \\
\hline \multirow[t]{2}{*}{ Chlorantraniliprole } & \multirow[t]{2}{*}{ SL } & 48 & 536.5 & 11,030 & 0.049 \\
\hline & & 144 & 93.2 & 1,120 & 0.083 \\
\hline \multirow[t]{2}{*}{ Chlorantraniliprole } & \multirow[t]{2}{*}{ SCL-1 } & 48 & 536.5 & 20,850 & 0.026 \\
\hline & & 144 & 93.2 & 3,070 & 0.030 \\
\hline \multirow[t]{2}{*}{ Chlorantraniliprole } & \multirow[t]{2}{*}{ SCL-2 } & 48 & 536.5 & 30,220 & 0.018 \\
\hline & & 144 & 93.2 & 3,510 & 0.027 \\
\hline
\end{tabular}

${ }^{a} \mathrm{LD}_{50}$ and $\mathrm{LC}_{50}$ values converted from data presented in Tables 2 and 3.

tion in the soil. Establishing both LD and LC toxicity data for the same time interval and evaluating toxicity on the same percentage basis (i.e., $\mathrm{LD}_{50}$ and $\mathrm{LC}_{50}$ ) the ratio can be determined. For an example, the 48-h $\mathrm{LD}_{50}$ of indoxacarb was 2,070 $\mathrm{ng}$ indoxacarb per $\mathrm{g}$ termite and the $48-\mathrm{h} \mathrm{LC}_{50}$ from the SL soil was 5,880 ng indoxacarb per $\mathrm{g}$ soil. By comparison, the $48-\mathrm{h} \mathrm{LD}_{50}$ was $536.5 \mathrm{ng}$ chlorantraniliprole per g termite and the $\mathrm{LC}_{50}$ from the SL soil was 11,030 ng chlorantraniliprole per $\mathrm{g}$ soil. Although indoxacarb has lower toxicity when topically applied, it seems to be taken up from the soil more readily by the termites than chlorantraniliprole; thus, lower concentrations in the soil are required for the termite to receive an equivalent dose. Therefore, a bioavailability ratio as defined in this study could be especially useful when comparing the bioavailability of two different insecticides with known LD and LC data.

The larger the bioavailability ratio the more insecticide is "available" to foraging termites. This is reflected in data presented (Table 4) as the SL soil had the largest bioavailability ratios followed by the decreasing values for SCL-1 and SCL-2 soils, respectively. This trend held for both indoxacarb and chlorantraniliprole at 48 and $144 \mathrm{~h}$. Indoxacarb was more bioavailable to termites compared with chlorantraniliprole, indicating that indoxacarb was more easily acquired from the soil by the termites. It is important to note that this does not reflect the inherent toxicity of the insecticide to termites but only the likelihood of termiticide uptake from the soil. Topical application $\mathrm{LD}$ data revealed that chlorantraniliprole is actually more toxic at a lower dose than indoxacarb. The calculation of bioavailability ratios for the two compounds suggest that at $48 \mathrm{~h}$, indoxacarb is 7.18-, 9.77-, and 9.83-fold more biologically available than chlorantraniliprole in SL, SCL-1, and SCL-2 soils, respectively. These ratios were even greater at $144 \mathrm{~h}$ and reflect a 22.31- (SL), 40.37- (SCL-1), and 18.07 (SCL2)-fold greater bioavailability for indoxacarb than chlorantraniliprole.

Insecticide factors that can contribute to differences in bioavailability include solubility, $\mathrm{K}_{\mathrm{oc}}$, and $\mathrm{K}_{\mathrm{ow}}$ (values reported above). These factors are reflective of the hydrophobicity of a particular chemical. Indox- acarb has a lower water solubility and a much higher $\mathrm{K}_{\mathrm{ow}}$ and $\mathrm{K}_{\mathrm{oc}}$ value compared with chlorantraniliprole. These differences reflect the higher hydrophobicity of indoxacarb compared with chlorantraniliprole and thus make it more lipophilic. The higher lipophilicity suggests that indoxacarb would have a greater affinity for the waxy cuticular layer of the termite. The comparatively high $\mathrm{K}_{\mathrm{oc}}$ value of indoxacarb means that it will be more tightly bound in soil, suggesting that it would be harder for that chemical to move from the soil to the termite. However, if indoxacarb is applied at a rate higher than its water solubility the AI may precipitate, thereby remaining available to foraging termites. Kamble and Saran (2005) reported $\mathrm{K}_{\mathrm{oc}}$ values of 3,787.34-11,934.68 for fipronil at termiticide application concentrations, which are much higher than the averaged $727 \mathrm{~K}_{\mathrm{oc}}$ value reported by Tingle et al. (2003). The higher $K_{\mathrm{oc}}$ value reported by Kamble and Saran (2005) may be due to precipitation of AI during adsorption assays, resulting in a higher apparent $K_{o c}$. High rate application of AIs with low solubility, such as fipronil, indoxacarb, and chlorantraniliprole, may result in precipitation of the compound in the soil. As a result, compounds that demonstrate higher lipophilicity may increase bioavailability to termites.

Correlation of bioavailability factors and \%OM are presented in Fig. 1. Regression equations for each plot are as follows: indoxacarb, $48 \mathrm{~h}(\mathrm{y}=0.4092-0.0718 \mathrm{x}$; $\left.R^{2}=0.9469\right)$; indoxacarb, $144 \mathrm{~h}(\mathrm{y}=2.1674-0.4204 \mathrm{x}$; $\left.R^{2}=0.9713\right)$; chlorantraniliprole, $48 \mathrm{~h}(\mathrm{y}=0.0539-$ $\left.0.0099 \mathrm{x} ; R^{2}=0.9810\right)$; and chlorantraniliprole, $144 \mathrm{~h}$ $\left(y=0.0905-0.0187 \mathrm{x} ; R^{2}=0.8964\right)$. Analysis indicated that bioavailability factors and $\mathrm{OM}$ were negatively correlated, suggesting that as OM increased there was an apparent decrease in AI availability.

The term "bioavailability" can have different meanings. One of the uses may refer to AI residues that are present and thus available to termites and measuring that by a particular response variable (i.e., mortality, LC, or lethal time [LT] data). Another use of the term could be more specific to the availability or tendency of an AI to be taken up from a particular soil by termites. Saran and Kamble (2008) reported bioavailability of fipronil, imidacloprid, and bifenthrin by us- 

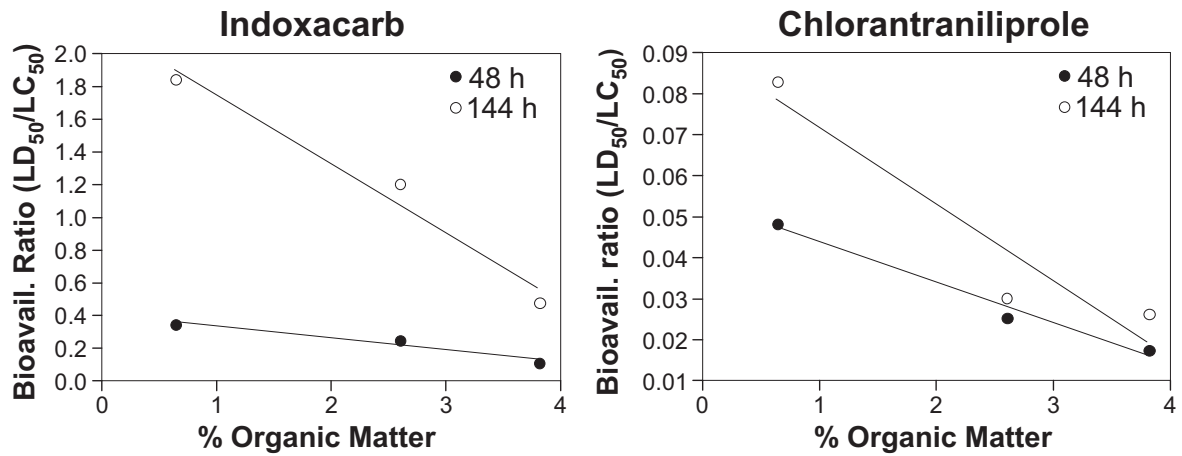

Fig. 1. Correlation between bioavailability ratios $\left(\mathrm{LD}_{50} / \mathrm{LC}_{50}\right)$ of indoxacarb and chlorantraniliprole to $R$. flavipes workers, and percentage of organic matter of three soils.

ing soil residue and LT toxicity data. This method is illustrative but does not take into account toxicokinetics; so, it is unknown whether longer reported LT values for different AIs are a result of internal and integumental factors or reduced uptake from soil. In addition, other researchers have used treated soil penetration bioassays reporting bioavailability as percentage of mortality of exposed termites (Gold et al. 1996; French and Ahmed 2005; Baker and Bellamy 2006). Although none of these methods for determining bioavailability are wrong, and in fact can be very illustrative, using a bioavailability ratio of $\mathrm{LD}_{50}$ data from topical application and $\mathrm{LC}_{50}$ data from treated soil exposure can provide more detail regarding the tendency of an insecticide to move from various soils to a termite. We propose that using bioavailability ratios may provide a more accurate assessment of the biological availability of a particular insecticide in soils to soil dwelling insects. Simply using a single descriptive parameter, such as soil exposure toxicity data or topical toxicity, may not fully represent the complex interaction of toxicokinetics and insecticide bioavailability.

\section{Acknowledgments}

We thank DuPont Corp. for providing the termiticides used in this study. This article is published as contribution 1299, Department of Entomology, Institute of Agriculture and Natural Resources, University of Nebraska, Lincoln.

\section{References Cited}

Baker, P. B., and D. E. Bellamy. 2006. Field and laboratory evaluation of persistence and bioavailability of soil termiticides to desert subterranean termite Heterotermes aureus (Isoptera: Rhinotermitidae). J. Econ. Entomol. 99: 1345-1353.

Campbell, W. V., D. A. Mount, and B. S. Heming. 1971. Influence of organic matter content of soils on insecticide control of the wireworm, Melanotus communis. J. Econ. Entomol. 64: 41-44.

Cordova, D., E. A. Benner, M. D. Sacher, J. J. Rauh, J. S. Sopa, G. P. Lahm, T. P. Selby, T. M. Stevenson, L. Flexner, S. Gutteridge, et al. 2006. Anthranilic diamides: a new class of insecticides with a novel mode of action, ryanodine receptor activation. Pestic. Biochem. Physiol. 84: 196214.

Felsot, A. S., and P. A. Dahm. 1979. Sorption of organophosphorus and carbamate insecticides by soil. J. Agric. Food Chem. 27: 557-563.

Felsot, A. S., and A. Lew. 1989. Factors affecting bioactivity of soil insecticides: relationships among uptake, desorption, and toxicity of carbofuran and terbufos. J. Econ. Entomol. 82: 389-395.

Forschler, B. T., and M. L. Townsend. 1996. Mortality of Eastern subterranean termites (Isoptera: Rhinotermitidae) exposed to four soils treated with termiticides. J. Econ. Entomol. 89: 678-681.

French, J.R.J., and B. M. Ahmed. 2005. A case for adopting a standardized protocol of field and laboratory bioassays to evaluate a potential soil termiticide. Sociobiology 46 : 551-562.

Getzin, L. W., and R. K. Chapman. 1960. The fate of phorate in soils. J. Econ. Entomol. 53: 47-51.

Gold, R. E., H. N. Howell, Jr., B. M. Pawson, M. S. Wright, and J. C. Lutz. 1996. Persistence and bioavailability of termiticides to subterranean termites (Isoptera: Rhinotermitidae) from five soil types and locations in Texas. Sociobiology 28: 337-363.

Harris, C. R. 1966. Influence of soil type on the activity of insecticides in soil. J. Econ. Entomol. 59: 1221-1225.

Harris, C. R. 1970. Laboratory evaluation of candidate materials as potential soil insecticides. III. J. Econ. Entomol 62: 782-787.

Harris, C. R., and B. T. Bowman. 1981. The relationship of insecticide solubility in water to toxicity in soil. J. Econ. Entomol. 74: 210-212.

Harris, C. R., and J. L. Hitchon. 1970. Laboratory evaluation of candidate materials as potential soil insecticides. II. J. Econ. Entomol 63: 2-7.

Harris, C. R., and J. H. Mazurek. 1966. Laboratory evaluation of candidate materials as potential soil insecticides. J. Econ. Entomol. 59: 1215-1221.

Kamble, S. T., and R. K. Saran. 2005. Effect of concentration on the adsorption of three termiticides in soil. Bull. Environ. Contam. Toxicol. 75: 1077-1085.

LeOra Software. 2003. PoloPlus ${ }^{\odot}$ probit and logit analysis. User's manual. LeOra Software, Berkeley, CA.

Nauen, R., and T. Bretschneider. 2002. New modes of action of insecticides. Pestic. Outlook 13: 241-245.

Nutting, W. L. 1990. Insecta: Isoptera, pp. 997-1032. In D. L. Dindal [ed.], Soil biology guide. Wiley, New York.

Saran, R. K., and S. T. Kamble. 2008. Concentration-dependent degradation of three termiticides in soil under lab- 
oratory conditions and their bioavailability to eastern subterranean termites (Isoptera: Rhinotermitidae). J. Econ. Entomol. 101: 1373-1383.

Systat Software, Inc. 2004. SigmaPlot ${ }^{\circledR} 9.0$ users guide. Systat Software, Inc., Point Richmond, CA.

Tingle, C.C.D., J. A. Rother, C. F. Dewhurst, S. Lauer, and W. J. King. 2003. Fipronil: environmental fate, ecotoxicology, and human health concerns. Rev. Environ. Contam. Toxicol. 176: 1-66.

[USDA] U.S. Department of Agriculture. 1993. Soil survey manual. U.S. Dep. Agric. Handbook No. 18. U.S. Department of Agriculture, Washington, DC.

[USEPA] U.S. Environmental Protection Agency. 2000. Pesticide fact sheet. Indoxacarb. U.S. Environmental Protection Agency. Washington, DC.
[USEPA] U.S. Environmental Protection Agency. 2008. Pesticide fact sheet: chlorantraniliprole. U.S. Environmental Protection Agency. Washington, DC.

Weesner, F. M. 1965. The termites of the United States-a handbook. The National Pest Control Association, Elizabeth, NJ.

Whitney, W. K. 1967. Laboratory tests with dursban and other insecticides in soil. J. Econ. Entomol. 60: 68-74.

Wing, K. D., M. Sacher, Y. Kagaya, Y. Tsurubuchi, L. Mulderig, M. Connair, and M. Schnee. 2000. Bioactivation and mode of action of the oxadiazine indoxacarb in insects. Crop Prot. 19: 537-545.

Received 17 May 2009; accepted 12 July 2009. 